\title{
The influence of player height on service performance in professional female tennis
}

\author{
Alejandro Sánchez-Pay ${ }^{a}$, José Antonio Ortega-Soto ${ }^{a}$, Bernardino J. Sánchez-Alcaráz ${ }^{a}$ \\ a University of Murcia, Murcia, Spain.
}

\section{ABSTRACT}

The aim of this study was to analyze the influence of female player height on service related parameters. Statistics on service performance and height of female players were gathered from the second round onwards in all Grand Slam tournaments. Findings showed that the taller the player, the higher the serve average speed, serve maximum speed in, number of aces and number of points won with the first service (\%), however, the number of double faults will increase as well. The Wimbledon surface (grass, fast court) favours taller players, who win a higher percentage of points with their first services here when compared to other surfaces. The findings of this study help to recognize the influence of height in female tennis in service related parameters, as well as the differences between the surfaces.

\author{
Key words: Biomechanics, \\ height, tennis, female. \\ Received: 28 August 2019 \\ Accepted: 30 September 2019 \\ Corresponding author: \\ Alejandro Sánchez-Pay, Sport \\ Science School, University of \\ Murcia, C/Argentina s/n \\ Campus de San Javier, Santiago \\ de la Ribera-San Javier Murcia \\ 30720, Spain. Email: \\ horne3@illinois.edu
}

INTRODUCTION

Currently, tactical analysis has been promoted by the continuous advance in technology, which allows for recording of great quantities of data and the creating of sport statistics in a simple and clear manner (Rein \& Memmert, 2016). Grand Slam tournament websites provide detailed information of matches being played and completed (Cross \& Pollard, 2009). The statistics gathered help to make a more comprehensive and better quality data analysis at the end of each match (Katić, Milat, Zagorac, \& Đurović, 2011), which can be used to determine different important influences on the game

Of all the information from official websites, the serve is the aspect on which the most data data (speed, direction, efficacy, effectiveness, etc.). This may be due to the fact that the serve is often considered to be a key factor in determining the result of a tennis match (Giampaolo \& Levey, 2013). It seems that high speed hitting, combined with a high percentage of first services, increases the probabilities of winning a match (Brody, 2003).

A lot of information related to the professional service exists, but information on the female service related information is scarcer. The aim of this study is to analyze the influence of female player's height on their serve performance.
Sample

The sample for this study consisted of a total of 580 sets from 252 matches played in all four Grand Slam matches (149 sets at Australian Open (AO), 134 at Roland Garros (RG), 146 at Wimbledon (W) and 151 at US Open (US), all of them in the ladies category. All matches from the second round onwards in all tournaments were recorded and analyzed. Unfinished matches, due to disqualification or withdrawal of a player, were not included.

\section{Procedure}

Ladies competition statistics of the four Grand Slam tournaments (AO, RG, W, \& US) were gathered. An Excel sheet was created to gather the information published at the official website of each tournament

(https://www.ausopen.com; https://www.rolandgarros.com; http://www.wimbledon.com/index.html and

https://www.usopen.org/index.html). The variables selected for the performance were: height of the female player, aces, double faults, $\%$ of first serve in, $\%$ of points won with the first serve, $\%$ of points won with the second serve, average serve speed $(\mathrm{km} / \mathrm{h})$ and maximum speed of the service $(\mathrm{km} / \mathrm{h})$. 


\section{Statistical analysis}

A descriptive analysis of the data included the mean (M) and standard deviation (SD). A frequency analysis was conducted which resulted in 9 height groups. The Kolmogorov Smirnov test was used to contrast the normality of the data for each variable. A lineal regression analysis $r^{2}$ was conducted to examine the possible influence of height on the selected variables. Analysis was performed with SPSS software for Windows (Version 20.0. Armonk, NY:IBM Corp.).

\section{RESULTS}

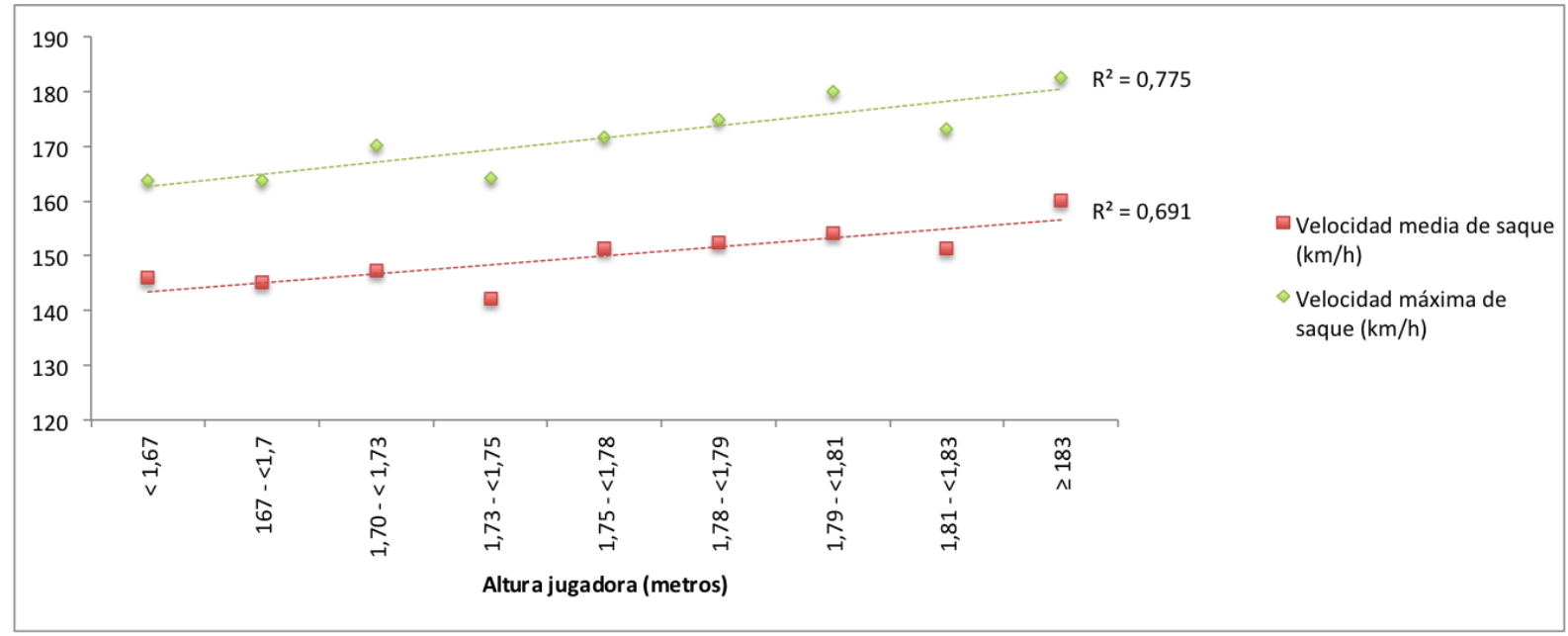

Figure 1. Relationships between the average serve speed and player height, and max. serve speed and player height.

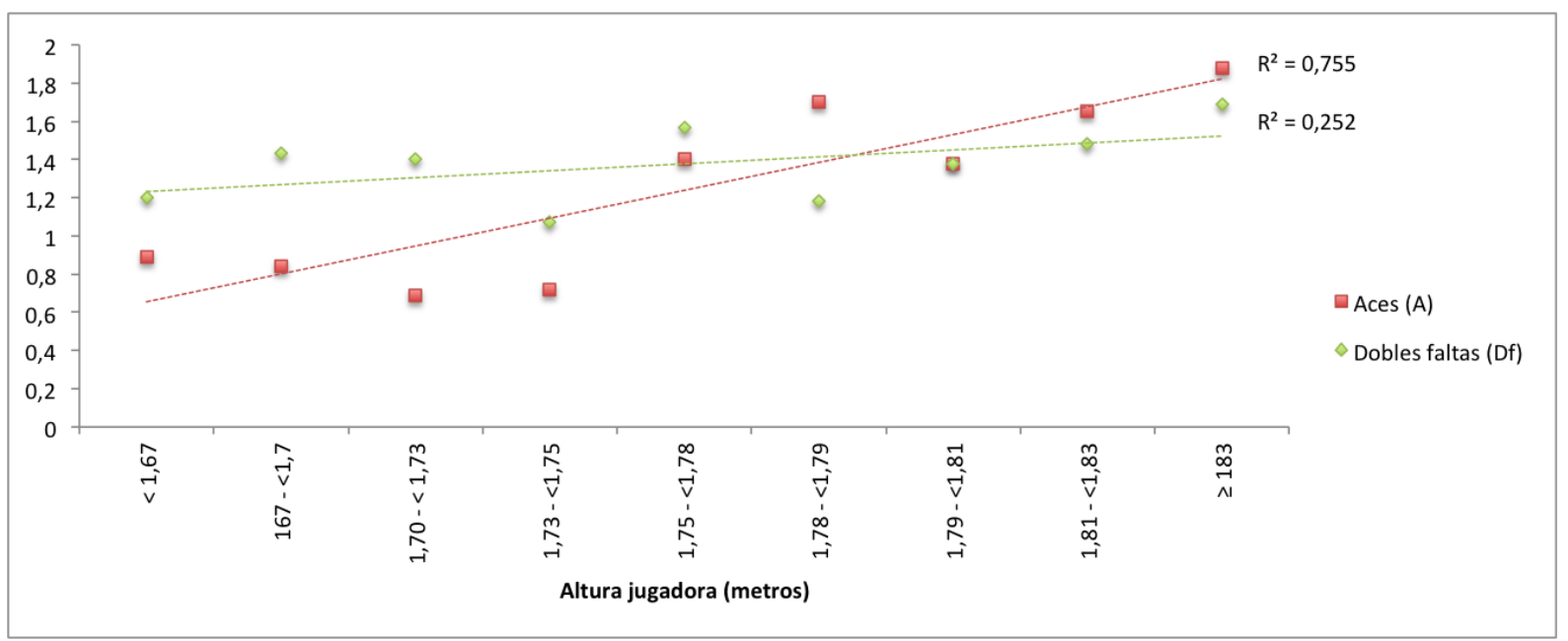

Figure 2. Relationship between the number of aces and player height, and double faults and player height. 


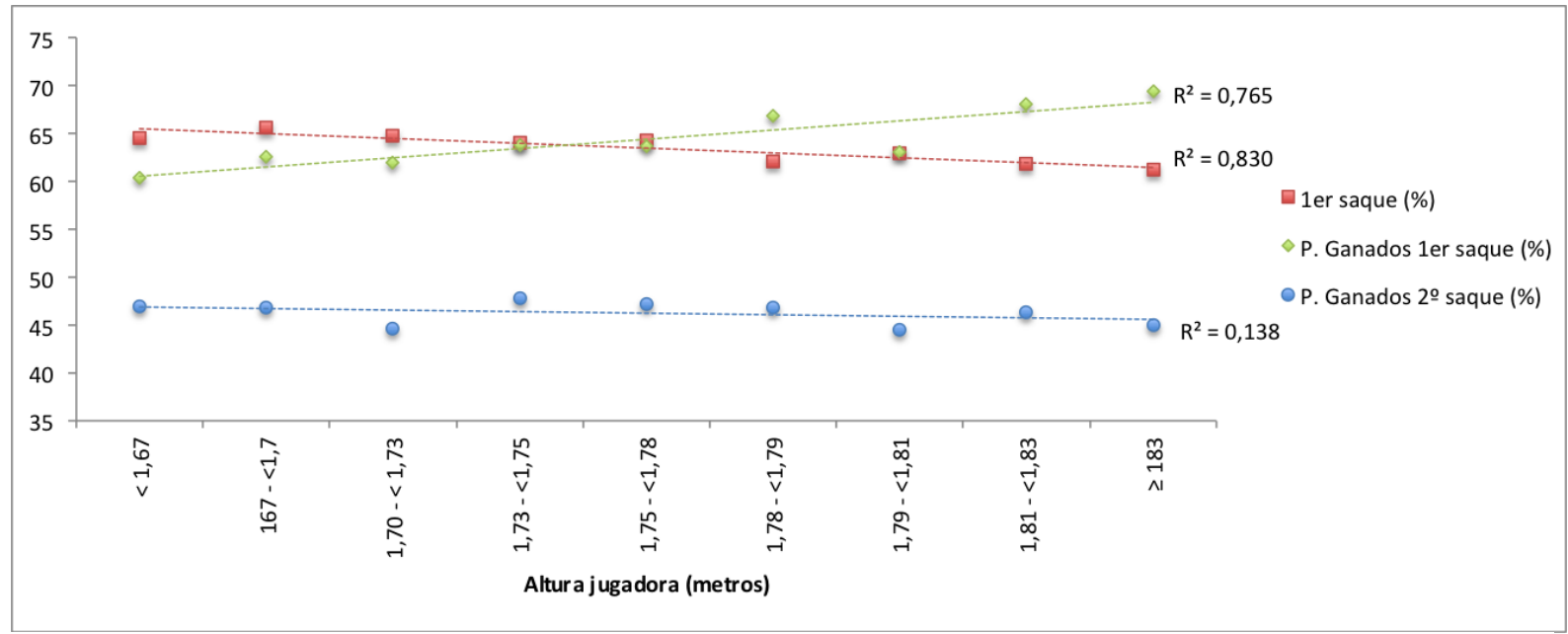

Figure 3. Relationships between the percentage of first serve in and player height, and points won with the first and second service player height.

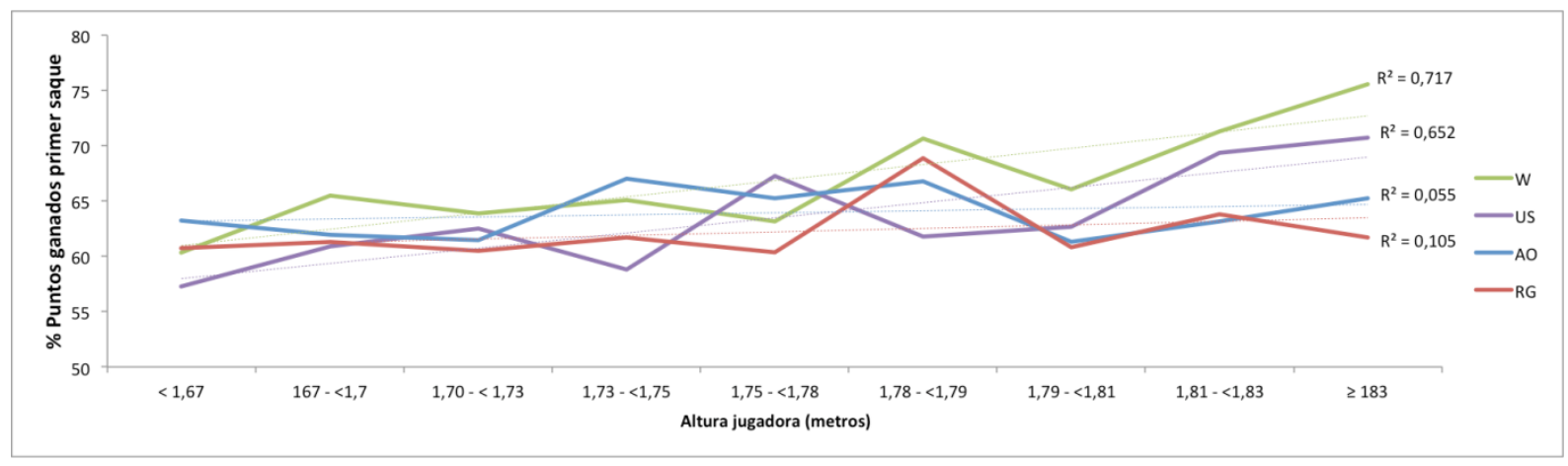

Figure 4. Relationships between player height and the percentage of points won with the first serve at each of the Grand Slam tournaments (W: Wimbledon. US: US Open. AO: Australian Open. RG: Roland Garros).

\section{COMMENTS}

Previous studies have shown that when the height of the player increases, so does the speed of the serve (Bonato et al., 2015; Fett, Ulbricht, \& Ferrauti, 2018). This same correlation is seen in this study, which uses competition statistics. From a biomechanical point of view, longer body segments allow for more powerful lever movements. This, together with the correct sequencing of body segments in the kinetic chain of the serve, it is possible for taller players to hit the ball harder.

Likewise, taller players are able to hit the ball at a higher point of impact, thus, they have more ability to open the service angles. This can be one of the reasons that the taller the player, the greater the number of aces (Figure 2). A faster service provides a greater number of aces but, in turn, a lower percentage of points won with the first serve (Figure 3).It could be the case that the taller the player, the greater the intention to win points straight from the service or an error in the return of the opponent. Thus as the height of the player increases, the number of points played with first serve decreases and the number of double faults increases (Figure 2).

The percentage of points won with the first serve has been one of the most analyzed parameters indicating performance and which have greater impact on the performance of the match (Katić et al., 2011). As we said above, the taller the player, in general, the greater the number of points won with the first serve $\left(r^{2}=0,765\right)$. One particular comment is that the surface does not seem to impact in the same way the relationship between player height and percentage of points won with the first serve on each surface (Figure 4). Thus, while at RG tournaments (clay surface, slow court) or $A O$ (hard surface, medium speed) the percentage of points won with the first serve increases slightly as the height of the player increases $\left(r^{2}=0,105\right.$ and $r^{2}=0,055$ respectively), at the US tournaments (hard surface, medium-fast speed) or W (grass 
surface, fast court) this percentage increases significantly. This relationship (\% of first serves won with height of the player) is stronger at Wimbledon. Wimbledon grass has a lower friction coefficient than the other surfaces

(O'Donoghue \& Ingram, 2001), thus, the loss of speed of the ball after bounce is the lowest of all of the four tournaments. Despite the introduction of the slower balls by the ITF on faster surfaces to balance the playing speed, and make rallies last similarly, there are still great differences in the different surfaces.

\section{CONCLUSIONS}

The findings of this study demonstrate the significant influence of the height of the female player in service performance. Taller players reach greater hitting speeds, increasing the percentage of points won with the first services and the number of aces. The fastest surface (grass) favours taller players, increasing the percentage of points won with the first serve when compared to the other surfaces.
RECOMMENDED ITF TENNIS ACADEMY CONTENT (CLICK BELOW)

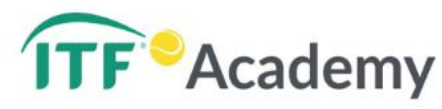

Copyright (c) 2019 Alejandro Sánchez-Pay, José Antonio Ortega-Soto, Bernardino J. Sánchez-Alcaráz

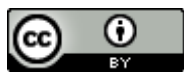

This text is under a Creative Commons BY 4.0 license

You are free to Share - copy and redistribute the material in any medium or format - and Adapt the content - remix, transform, and build upon the material for any purpose, even commercially under the following terms:

Attribution: You must give appropriate credit, provide a link to the license, and indicate if changes were made. You may do so in any reasonable manner, but not in any way that suggests the licensor endorses you or your use.

CCBY4.0 license terms summary CCBY4.0license terms

\section{REFERENCES}

Bonato, M., Maggioni, M. A., Rossi, C., Rampichini, S., La Torre, A., \& Merati, G. (2015). Relationship between anthropometric or functional characteristics and maximal serve velocity in professional tennis players. The Journal of Sports Medicine and Physical Fitness, 55(10), 1157-1165.

Brody, H. (2003). Serving strategy. ITF Coaching and Sport Science Review, 31, 2-3.

Cross, R., \& Pollard, G. (2009). Datos sobre partidos de individual masculinos en Grand Slam 1991-2009. La velocidad del servicio y otros datos relacionados. ITF Coaching and Sport Science Review, 16(49), 8-10.

Fett, J., Ulbricht, A., \& Ferrauti, A. (2018). Impact of physical performance and anthropometric characteristics on serve velocity in elite junior tennis players. Journal of Strength and Conditioning Research, 1(1), 1-11, https://doi.org/10.1519/JSC.0000000000002641

Giampaolo, F., \& Levey, J. (2013). Championship tennis. Human Kinetics.

Katić, R., Milat, S., Zagorac, N., \& Đurović, N. (2011). Impact of game elements on tennis match outcome in Wimbledon and Roland Garros 2009. Collegium Antropologicum, 35(2), 341-346.

O'Donoghue, P., \& Ingram, B. (2001). A notational analysis of elite tennis strategy. Journal of Sports Sciences, 19(2), 107-115, https://doi.org/10.1080/026404101300036299

Rein, R., \& Memmert, D. (2016). Big data and tactical analysis in elite soccer: future challenges and opportunities for sports science. SpringerPlus, https://doi.org/10.1186/s40064-016-3108-2 